workforce in the future. Consequently, if we, as a discipline, are to commit ourselves to addressing the issues surrounding gender pay equity and workforce shortfalls, we need to go beyond STEM.

\title{
References
}

Bergman, M., \& Jean, V. (2016). Where have all the "workers" gone? A critical analysis of the underprepresentativeness of our samples relative to the labor market in the industrial-organizational psychology literature. Industrial and Organizational Psychology, 9, 84-113.

Bureau of Labor Statistics. (2015). STEM crisis or STEM surplus? Yes and yes. Monthly Labor Review. Retrieved from https://www.bls.gov/opub/mlr/2015/article/ stem-crisis-or-stem-surplus-yes-and-yes.htm.

Bureau of Labor Statistics. (2016). Women's earnings 83 percent of men's, but vary by occupation. TED: The Economics Daily. Retrieved from https://www.bls.gov/opub/ted/2016/ womens-earnings-83-percent-of-mens-but-vary-by-occupation.htm

Bureau of Labor Statistics. (2017). Employed persons by detailed occupation, sex, race, and Hispanic or Latino ethnicity. Labor Force Statistics from the Current Population Survey. Retrieved from https://www.bls.gov/cps/cpsaat11.htm

Engineering.com. (2015). Mike Rowe asks who took skilled trades out of STEM education. Retrieved from https://www.engineering.com/Blogs/tabid/3207/ArticleID/9752.

ManpowerGroup. (2016). The 10 hardest jobs to fill. Retrieved from http://www.manpowergroup.us/ campaigns/talent-shortage/.

Miner, K, N., Walker, J. M., Bergman, M. E., Jean, V. A., Carter-Sowell, A., January, S. C., \& Kaunas, C. (2017). From "her" problem to "our" problem: Using an Individual lens versus a social structural lens to understand gender inequity in STEM. Industrial and Organizational Psychology: Perspectives on Science and Practice, 11(2), 267-290.

Scandura, T., \& Williams, E. (2000). Research methodology in management: Current practices, trends, and implications for future research. Academy of Management Journal, 43, 1248-1264.

\section{STEM-ming the Tide: A Different Approach to Shaping Diverse Participation in STEM Careers}

Valerie N. Streets, James N. Kurtessis, Lindsay Northon, and Alex Alonso Society for Human Resource Management

Miner et al. (2018) have steered the trajectory of gender and STEM research in a new direction.

However, while a shift in conceptualizing women's STEM participation is needed, the distinction between individual and social-structural lenses may not be the best place to focus our efforts. Although the current empha-

Valerie N. Streets, Society for Human Resource Management; James N. Kurtessis, Society for Human Resource Management; Lindsay Northon, Society for Human Resource Management; Alex Alonso, Society for Human Resource Management.

Correspondence concerning this article should be addressed to Valerie N. Streets, Society for Human Resource Management, 1800 Duke St., Alexandria, VA 22314. E-mail: valerie.streets@shrm.org 
sis on individual-level explanations and solutions is not sufficient and can be problematic, a social-structural lens does not provide the push we need to truly treat gender inequity as "our" problem. Instead, we believe that the best course of action is to delineate specific, actionable, and inclusive recommendations for encouraging women's participation in STEM. Before describing specific recommendations, we first discuss how to make this discourse more inclusive.

\section{Should We Adjust the Lenses or the Frames?}

Women's underrepresentation in STEM fields is neither a new nor unique issue, and gender inequity has been observed in numerous other contexts. For example, from awareness of gender disparities in leadership emerged the "Lean In" movement. In her book Lean In: Women, Work, and the Will to Lead, Sheryl Sandberg (2013) aimed to empower women by urging them to take a seat at the table. However, a major criticism of Sandberg's argument is echoed by Miner et al. (2018); spreading the Lean In gospel is a way of fixing "her" problem. The solutions for gender disparity were portrayed through an individual-level lens. Doing this excludes men from the picture. It seems we are learning from these mistakes, but shifting to a social-structural lens does not in and of itself invite men into the conversation.

The recommended emphasis on social-structural explanations and interventions over individual ones is an improvement upon much of the extant gender and STEM research, yet it is still lacking. A social-structural lens may lead to solutions that do not solely aim to "fix women" (i.e., providing women with thought and behavioral patterns to take a seat at the table) but instead address broader cultural issues. However, the discourse needs to change further. Rather than emphasizing a social-structural focus, we should prioritize a collective approach.

In each of the myths discussed by Miner et al., the social-structural lens shifts the blame from women and their perceived shortcomings to a masculine STEM culture. This shift is not entirely unfounded, but it is unlikely to lead to constructive discourse or action. The nonprofit organization Catalyst found that over $70 \%$ of men claim that women and men have access to similar jobs. They cite discomfort in discussing inequality as a top barrier to gender parity (Thorpe-Moscon, 2017). To raise both the awareness and partnership of men, the dialogue must engage them.

Rather than looking at structural issues like masculine cultures, it may be more productive to create discussions that are both actionable and inclusive. That is, let's change the way we are framing our treatment of this topic. Rather than focusing on the issues of a masculine STEM culture, let's explore concepts linked to women's STEM participation that are less divisive. For example, positive marginality is the perception that belonging to 
a nondominant group can be advantageous rather than oppressing. This phenomenon has been displayed by women in STEM majors and careers (Streets, 2016), and provides the opportunity to look to the women who are pursuing STEM, rather than those who left, to understand retention and participation. Similarly, embeddedness, or the varied types of commitment individuals feel toward organizations and careers, has been demonstrated among men and women college students as a key driver in their STEM retention (Morganson, Major, Streets, Litano, \& Myers, 2015). Like positive marginality, this perspective focuses on people who are actively in STEM fields, again analyzing what is going right in STEM instead of what is going wrong. Both of these concepts fall under the individual-level lens but may invite more productive and inclusive discussions.

\section{Are Some Answers Right in Front of Us?}

We agree with Miner et al. (2018) that this is an area with rich potential for industrial and organizational (I-O) psychology to have an impact. Yet the practical recommendations in the focal article do not provide plentiful or concrete suggestions. As important as it is to discuss our conceptualization of the gender disparity in STEM, we should use this forum to establish some clear directions we can take moving forward in both research and practice. To better understand I-O psychology's potential role in this issue, we may not have to look very far-like to our not-so-distant cousin, human resources (HR).

HR provides an interesting case study, as it parallels the issues in the STEM domain. HR is currently a profession composed primarily of women. Women hold 75\% of HR employee positions and HR managerial roles (BLS, 2017). For many years, HR had difficulty obtaining a seat at the table. This may be in part because that table was usually occupied by men, who may have given little credence to the field and the women employed in it. Traditionally, many of HR's functions were centered around traditionally feminine (or tactical) tasks (e.g., serving as employee relations specialist or playing the role of compliance manager; Taylor \& Stern, 2009). However, this has changed. In many organizations, $\mathrm{HR}$ is now a critical leader at the table and is engaged in highly strategic tasks. Much of this advancement was accomplished without treating it as a gendered issue. Generally, the business case was made and demonstrated for the crucial role of HR for organizational functioning, thereby engaging men and women alike. How might we translate HR's path to that of women pursuing STEM careers? Tracing HR's road to the C-suite could provide valuable insight that translates to the STEM domain.

Additionally, we can look to HR as an organizational gatekeeper. HR professionals are a great resource to tap regarding women's STEM careers. From a research standpoint, we should look to HR to better understand why 
and how women persist and find success in STEM careers. Much of the research published by I-O psychologists on the topic involves student samples.

HR's accumulation of data from application to termination likely provides a key source of insights into the specific areas in the workplace and job market that are most problematic and advantageous for women in STEM. For example, talent acquisition professionals have their fingers on the pulse of an applicant pool. Rather than working to uncover issues in the bridge from education to employment, I-O psychology can ask HR, freeing up our resources to develop societal interventions. Regarding practice, a number of HR functions could be shaped to foster a more gender-inclusive environment. Crafting gender-neutral job descriptions and advertisements, emphasizing objective selection tools and compensation bands, training managers with regard to inclusion, and initiating discussions on this topic are all ways HR can work to advance gender parity in STEM professions.

HR is also facing a need for change marked by a greater emphasis on talent analytics and technology. Not only is the connection between women and STEM an issue I-O psychology can help address, it is an issue occurring on our own turf. Overwhelmingly, HR professionals and thought leaders recognize the movement toward analytics and technology as well as its importance.

However, as members of an association working to support HR professionals, we see the tension surrounding this change. In many organizations technology is limited to applicant tracking systems although more cuttingedge technology is available and promising for improving HR and organizational functioning. Similarly, although many HR professionals will note in conversation that they are not adept with analytics, most agree that those skills are crucial to the HR profession now and in the future. Thus, getting more women into STEM is not a matter limited to traditional STEM occupations-HR has a growing demand for STEM skills and is facing the same difficulties. Fields like HR that have a need for STEM but do not have the masculine culture associated with STEM may be a great initial bridge for retaining women in the discipline. Highlighting a more diverse set of career options may entice more girls and young women to pursue and remain in STEM educational programs, as they will be able to utilize the skills to which they are drawn while experiencing potentially less isolating organizational cultures.

\section{Where Do We Go From Here?}

We strongly believe that the I-O psychology community can and should play a role in encouraging and supporting women's participation in STEM and that actionable recommendations are what is needed to push this worthwhile agenda forward. We therefore provide the following recommendations: 
1. I-O psychologists should create and promote a dialogue about women in STEM that is inclusive of men and women. To do so we might look to prior research, such as that on superordinate goals (e.g., Sherif, Harvey, White, Hood, \& Sherif, 1961), to determine how best to frame our discussion and recommendations in a manner that is inclusive and relevant to men and women alike.

2. To understand how women can obtain and maintain a seat at the table we may need to look no further than HR. Understanding the rise of HR-from a cost center for transactional tasks to a valued strategic partner-may help us to understand how women's participation in STEM can be framed in ways other than gender equality.

3. I-O psychologists should leverage increasingly ubiquitous HR data to understand how and why women enter, find success in, and leave STEM occupations. The data to answer many of our questions and develop further recommendations may already be available to us.

4. In considering women's participation in STEM, we may be well-served by examining how such skills are being enhanced in professions such as HR. Further, enhancing STEM skills among the current workforce in professions such as HR may be a backdoor approach for enhancing women's participation in STEM more broadly.

\section{Conclusion}

We commend Miner et al. (2018) for bringing not only the issue of women's underrepresentation in STEM to the forefront of I-O psychology, but also a call to revise the general approach for addressing it. However, we encourage scholars and practitioners to look beyond the individual/social-structural paradigm as the field builds a strategy for tackling this issue. If the end goal is greater inclusion, let's keep the process for getting there inclusive. We also urge the I-O psychology community to not only look within but also to leverage the insights and resources of related disciplines (e.g., social psychology, $\mathrm{HR}$ ) to help us to understand and encourage women's participation in STEM careers.

\section{References}

Bureau of Labor Statistics, U.S. Department of Labor. (2017). Women in the labor force: A data book. Retrieved from https://www.bls.gov/opub/reports/womens-databook/2017/home.htm.

Miner, K. N., Walker, J. M., Bergman, M. E., Jean, V. A., Carter-Sowell, A., January, S. C., \& Kaunas, C. (2018). From "her" problem to "our" problem: Using an individual lens versus a social structural lens to understand gender inequity in STEM. Industrial and Organizational Psychology: Perspectives on Science and Practice, 11(2), 267-290.

Morganson, V. M., Major, D. A., Streets, V. N., Litano, M. L., \& Myers, D. P. (2015). Using embeddedness theory to understand and promote persistence in STEM majors. Career Development Quarterly, 63, 348-362. 
Sandberg, S. (2013). Lean in: Women, work, and the will to lead. New York, NY: Random House.

Sherif, M., Harvey, O. J., White, B. J., Hood, W. R., \& Sherif, C. W. (1961) Intergroup conflict and cooperation: The robbers cave experiment. Norman, OK: University of Oklahoma Book Exchange.

Streets, V. N. (2016). Reconceptualizing women's STEM experiences: Building a theory of positive marginality (Doctoral dissertation). Retrieved from ProQuest Dissertations \& Theses Global. (Accession No. 10248358).

Taylor, J. C., \& Stern, G. M. (2009). The trouble with HR: An insider's guide to finding and keeping the best people. New York, NY: AMACOM.

Thorpe-Moscon, J. (2017). Turn perception into reality. Retrieved from http://www.catalyst.org/ knowledge/turn-perception-reality- 0 .

\section{Bridging Individual and Social-Structural Perspectives}

Kristi Lavigne and Rachel Rauvola

Saint Louis University

A paradigm shift toward a social-structural perspective may provide a better understanding of the gender inequity in STEM fields than its predecessor, but this perspective falls prey to the focal article authors' (Miner et al., 2018) own criticisms: It offers an incomplete account of the phenomenon of interest. We argue that a multilevel systems perspective is the most appropriate approach when trying to understand any issue, especially an issue as dense as gender inequity in STEM. A deliberate effort to understand this phenomenon dynamically across levels and time can expand the scope of industrial and organizational (I-O) psychologists' influence and can better protect us against interventions that result in unintended, adverse outcomes. Below, we discuss the importance of looking across multiple levels simultaneously to understand the temporal and interactional nature of individual and social-structural constructs. Without this depth of understanding, a disruption of the current structure may lead to an unstable, or unanticipated, new structure.

One assumed advantage of a social-structural perspective is its ability to better explain gender inequity in STEM. Unfortunately, few studies consider both individual and social-structural causal factors simultaneously and comparatively. There is reason to believe that an individual perspective contributes meaningful incremental variance in explaining gender inequity. For example, some research suggests that stereotypes more accurately reflect the target when the scores from the stereotype holders are aggregated to the

Kristi Lavigne, Saint Louis University; Rachel Rauvola, Saint Louis University.

Correspondence concerning this article should be addressed to Kristi Lavigne, Saint Louis University, Saint Louis, MO. E-mail: kristi.lavigne@slu.edu 